\title{
Erratum to: Using the Census Bureau's surname list to improve estimates of race/ethnicity and associated disparities
}

\author{
Marc N. Elliott - Peter A. Morrison - Allen Fremont • \\ Daniel F. McCaffrey $\cdot$ Philip Pantoja $\cdot$ Nicole Lurie
}

Published online: 30 October 2009

(C) Springer Science+Business Media, LLC 2009

\section{Erratum to: Health Serv Outcomes Res Method (2009) 9:69-83 DOI 10.1007/s10742-009-0047-1}

Unfortunately, in the article "Using the Census Bureau's surname list to improve estimates of race/ethnicity and associated disparities", Health Serv Outcomes Res Method, Table 7 has been incorrectly published in Vol. 9/Iss. 2; page 80 .

The corrected Table 7 is presented below:

The online version of the original article can be found under doi:10.1007/s10742-009-0047-1.

M. N. Elliott $(\bowtie) \cdot$ A. Fremont $\cdot$ P. Pantoja

RAND Corporation, 1776 Main Street, Santa Monica, CA 90407, USA

e-mail: elliott@rand.org

A. Fremont

e-mail: fremont@rand.org

P. Pantoja

e-mail: pantoja@rand.org

P. A. Morrison

RAND Corporation, 3 Eat Fire Springs Road, Nantucket, MA 02554, USA

e-mail: peterm3636@aol.com

D. F. McCaffrey

RAND Corporation, 4570 Fifth Avenue, Suite 600, Pittsburgh, PA 15213, USA

e-mail: danielm@rand.org

N. Lurie

RAND Corporation, 1200 South Hayes Street, Arlington, VA 22202, USA

e-mail: lurie@rand.org 


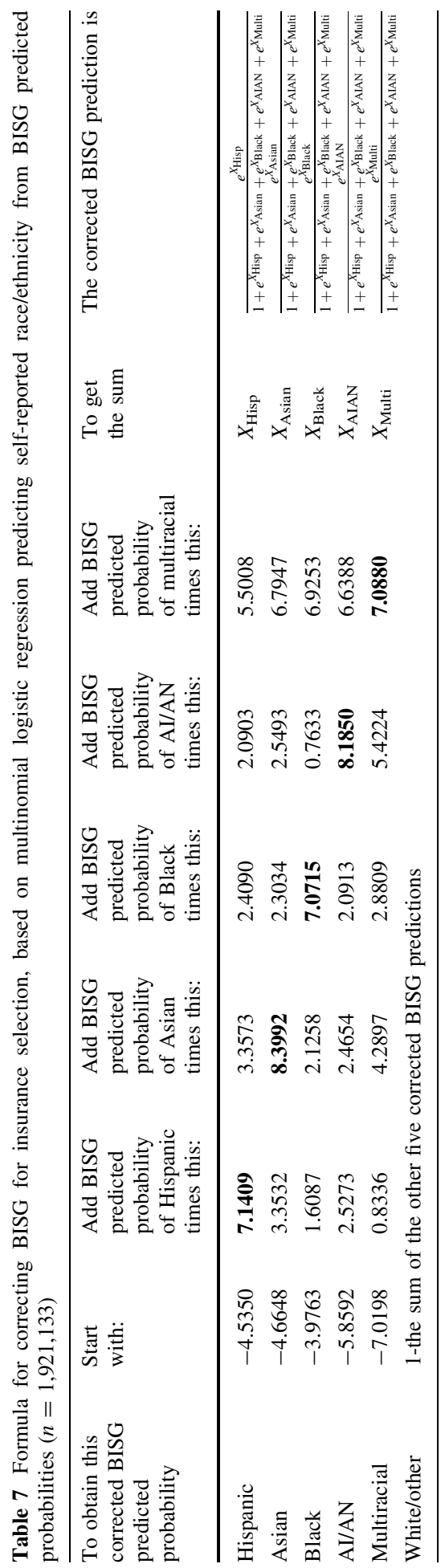

